\title{
Adaptive preferential selection of young coccinellid hosts by the parasitoid wasp Dinocampus coccinellae (Hymenoptera: Braconidae)
}

\author{
Michael E.N. MAJERUS ${ }^{1}$, Irene E. GEOGHEGAN ${ }^{2}$ and TAmsin M.O. MAJERUS ${ }^{1}$ \\ ${ }^{1}$ Department of Genetics, Downing Street, Cambridge, CB2 3EH, UK; e-mail: menm@mole.bio.cam.ac.uk \\ ${ }^{2}$ Scottish Crop Research Institute, Invergowrie, Dundee, DD2 5DA, UK
}

\begin{abstract}
Key words. Parasitoid, host selection, host discrimination, Dinocampus coccinellae, Braconidae, Coccinella septempunctata, Coccinellidae
\end{abstract}

\begin{abstract}
Dinocampus coccinellae females which eclose in mid-summer have the opportunity to oviposit in overwintered or in newly eclosed coccinellid hosts. Given the short further longevity of overwintered hosts, offspring fitness would be increased by ovipositing preferentially in young hosts. Laboratory choice tests show that female $D$. coccinellae do exhibit such a preference.
\end{abstract}

\section{INTRODUCTION}

Parasitoids encounter a series of potential hosts in which they might oviposit. These may vary in suitability as hosts. Natural selection should thus favour the development of host recognition systems which allow recognition of the most suitable hosts. Evidence of the ability of parasitoids to select more suitable hosts has been obtained in several studies, whether the difference in host suitability be dependent on host species (Kraaijeveld et al., 1995), host developmental stage (van Alphen, 1980; Luck et al., 1982), host nutritional state (Kouamé \& Mackauer, 1991), host parasitisation status (Pijls et al., 1995) or host age within a developmental stage (van Alphen \& Drijver, 1982; Hurst et al., 1998). In some cases, the criteria determining host quality centre on the suitability of the host for larval development, in others it is the ease or rate at which oviposition may be achieved that is critical (Godfray, 1994).

The hymenopterous parasitoid Dinocampus coccinellae (Schrank) exclusively parasitises coccinellids of the subfamily Coccinellinae (Hodek \& Honěk, 1996). In Britain, this wasp almost exclusively attacks adult coccinellids, showing considerable reluctance to oviposit in preimaginal stages if adults are available (Geoghegan et al., 1998). The rarity of parasitisation of pre-imaginal stages is probably due to the fact that, in most years, new adult coccinellids eclose and become available as hosts before the overwintering generation has died. This means that wasps which have overwintered as eggs or first generation larvae within hosts, will, on eclosion, have adult coccinellids of two generations available to them: old overwintered adults which are likely to die within a short time, and recently eclosed adults which will overwinter. Intuitively, it seems probable that newly eclosed adult coccinellids will be more suitable as hosts than old adults. If so, selection may have acted on $D$. coccinellae to maximise its reproductive success by selecting young rather than old coccinellid adults for oviposition.
In this paper we describe choice tests designed to address the hypothesis that female $D$. coccinellae can distinguish between old, overwintered and young, newly eclosed adult Coccinella septempunctata $\mathrm{L}$.

\section{MATERIALS AND METHODS}

Stocks

Wasps were obtained by collecting samples of C. septempunctata in the Dundee and Cambridge areas, between March and June 1997. Ladybirds were fed in captivity on pea aphids, Acyrthosiphon pisum (Harris), to allow wasps to emerge. Following eclosion, wasps were kept in Petri dishes, with time and date of eclosion recorded, and fed on honey-water, at approximately $21^{\circ} \mathrm{C}, 16 \mathrm{~L}: 8 \mathrm{D}$, until used in tests.

The "old" C. septempunctata used were collected as adults from overwintering sites around Cambridge in March 1997. These ladybirds were assumed to have eclosed the previous summer. They were removed to the laboratory where they were fed on an alternate diet of pea aphids and an artificial food (Majerus et al., 1989) for 20 days, and thereafter on pea aphids daily. Thirty days after collection, they were mated and allowed to oviposit. Eggs were collected daily. Adults were retained for a further 40-50 days before use in tests. The period of $60+$ days retention was to ensure that none of the field collected adults used in tests were infected with $D$. coccinellae. Adults which gave rise to cocoons of $D$. coccinellae during this period (none after day 27) were removed from the stock.

"Young" C. septempunctata were progeny from the old adults. Eggs collected from the old stock were allowed to hatch and were reared on pea aphids. On eclosion, the young adults were sexed and kept in dishes containing only one sex, on a diet of pea aphids for 10-20 days before testing. All ladybirds were kept at approximately $21^{\circ} \mathrm{C}, 16 \mathrm{~L}: 8 \mathrm{D}$, throughout the work.

\section{Test procedures}

Two types of test were conducted. In the first, 10 old and 10 young $C$. septempunctata, match-paired for sex and size (by eye) were placed in a $14 \mathrm{~cm}$ Petri dish. A single wasp, that had eclosed between five and seven days previously, was introduced. Observations of all interactions between the wasp and the beetles were recorded over a three hour period. Wasps were then removed. Behaviours observed were categorised, after Richerson \& DeLoach (1972), as: pursuance and investigation 
of host (PI); ovipositional stance (OS); or ovipositional attack (OA). Ten replicates were made, five using female ladybirds and five using males. Ladybirds were then retained in the laboratory and fed on an excess of pea aphids for 60 days. Emergence of wasp larvae from any coccinellid and the date of death of any coccinellid were recorded. Ladybirds that died during the observation period were dissected to determine whether they had been infected.

In the second type of test, one old and one young C. septempunctata, match-paired for sex and size (by eye) were placed in a $9 \mathrm{~cm}$ Petri dish. A single wasp (5-7 days old) was introduced The ladybird to which the wasp first directed an oviposition attack was noted. The wasp was left with the coccinellids for 24 hours before removal. Twenty-five replicates were made for each sex. Following the tests, beetles were killed by freezing and were dissected within $72 \mathrm{~h}$ to determine whether they had been parasitised. The number of individuals which contained parasitoid eggs and the number of eggs found in each were recorded.

\section{RESULTS}

The results of the first type of test, shown in Table 1, show that wasps exhibit PI of old and young wasps equally $\left(\chi^{2}=0\right.$, d.f. $=1, p=1$ for sexes combined). However, $O S$ and $O A$ were directed significantly more towards young rather than old females (for OS, $\chi^{2}=$ 4.566 , d.f. $=1, \mathrm{p}<0.05$; for OA, $\chi^{2}=4.0$, d.f. $=1, \mathrm{p}<$ 0.05 ). For male hosts, the higher level of OS directed towards young compared to old beetles was not significant $\left(\chi^{2}=0.190\right.$, d.f. $\left.=1, p>0.05\right)$, but that of OA was significant $\left(\chi^{2}=5.0\right.$, d.f. $\left.=1, \mathrm{p}<0.05\right)$.

TABLE 1. Total number of interactions of a single $D$. coccinellae with 10 old and 10 young females or males of C. septempunctata (for five runs with each sex).

\begin{tabular}{|c|c|c|c|c|c|c|}
\hline \multirow[t]{2}{*}{ Host sex } & \multicolumn{3}{|c|}{$\begin{array}{c}\text { Old hosts } \\
\text { No. of interactions }\end{array}$} & \multicolumn{3}{|c|}{$\begin{array}{c}\text { Young hosts } \\
\text { No. of interactions }\end{array}$} \\
\hline & PI & OS & $\mathrm{OA}$ & PI & OS & $\mathrm{OA}$ \\
\hline$\overline{\text { Female }}$ & 80 & 42 & 24 & 84 & 64 & 40 \\
\hline Male & 72 & 40 & 15 & 68 & 44 & 30 \\
\hline Total both sexes & 152 & 82 & 39 & 152 & 108 & 70 \\
\hline
\end{tabular}

Table 2 summarises data on the longevity of ladybirds (excluding those from which wasps emerged) and on their parasitisation and mortality following the tests. There were no significant differences between male and female hosts. The mean longevity of both female and male hosts was significantly less for old compared to young hosts (Mann-Whitney $U$ test adjusted for ties; for females $\mathrm{W}=$ 915, $\mathrm{p}<0.0001$; for males $\mathrm{W}=922.5, \mathrm{p}<0.0001)$. The proportion of infected hosts that died before wasps com- pleted development was significantly greater for old compared to young hosts $\left(\chi^{2}=21.333\right.$, d.f. $\left.=1, p<0.001\right)$.

The results of tests offering a wasp a single old and young host are summarised in Table 3. Although for both females and males more initial attacks were directed to young rather than old hosts, the difference is not significant, even when the sexes are combined $\left(\chi^{2}=2\right.$, d.f. $=1$, $\mathrm{p}>0.05)$. There was no significant difference in the number of young compared to old ladybirds, or in the number of males compared to females found to be infected. However, the total number of eggs found in young hosts was significantly greater than the number found in old hosts, both for females $\left(\chi^{2}=19.355\right.$, d.f. $=1$, $p<0.001)$ and males $\left(\chi^{2}=9.470\right.$, d.f. $\left.=1, p<0.001\right)$. It may be noted that the number of eggs found in females was significantly greater than the number found in males, both for old $\left(\chi^{2}=4.654\right.$, d.f. $\left.=1, p<0.05\right)$ and young $\left(\chi^{2}\right.$ $=12.188$, d.f. $=1, p<0.001)$ ladybirds.

\section{DISCUSSION}

Dinocampus coccinellae females were not initially attracted more to young compared to old hosts. However, initial PI of young ladybirds was more often followed by the wasp taking up an OS and performing an OA than it was when initial PI was directed towards old ladybirds. The wasps thus appear to be assessing the suitability of individual ladybirds as potential hosts before ovipositing in them. This behaviour appears to be adaptive as the number of wasps that successfully emerged from hosts was greater in young than in old hosts, both in absolute terms and as a proportion of those infected. This is not surprising given the higher rate of mortality of the old ladybirds during the work, for larvae of $D$. coccinellae die if their host dies (M. Majerus, pers. obs.). By preferring to oviposit in young rather than old ladybirds, the wasps reduce the likelihood that the hosts that they have oviposited in will die before the wasp's progeny have completed larval development.

The evidence thus supports a correlation between host acceptance and host quality. Such a correlation has been shown in a variety of other studies, with a variety of criteria affecting host quality. A number of workers have shown that trichogrammatid egg parasitoids favour attack into young compared with old host eggs (Marston \& Ertle, 1969; Pak, 1986), and that the age of host eggs is negatively correlated to its quality as a host to trichogrammatids (Lewis \& Redlinger, 1969; Juliano, 1982; Strand, 1986). The instar at which hosts are attacked has also been shown to reflect host quality in a number of cases (e.g. Hooper \& King, 1984; Nechols \& Kikuchi,

TABLE 2. Mean longevity and infection data, and the number of individuals of $C$. septempunctata which survived following tests in which single $D$. coccinellae were offered 10 old and 10 young coccinellids.

\begin{tabular}{lccccrr}
\hline Host sex & Host age & Mean longevity* & $\begin{array}{c}\text { No. of wasps } \\
\text { produced }\end{array}$ & $\begin{array}{c}\text { No. infected } \\
\text { which died }\end{array}$ & $\begin{array}{c}\text { No. uninfected } \\
\text { which died }\end{array}$ & No. survived \\
\hline Female & old & 27.630 & 4 & 6 & 34 & 6 \\
& young & 57.235 & 26 & 1 & 3 & 20 \\
Male & old & 24.022 & 4 & 8 & 30 & 8 \\
& young & 55.895 & 16 & 1 & 6 & 27 \\
\hline
\end{tabular}

* Hosts from which wasps successfully emerged are excluded. Longevity of those surviving to day 60 is assumed to be 60 days. 
TABLE 3. Number of cases of the first $D$. coccinellae oviposition attack directed at old and young $C$. septempunctata and the parasitisation data from those hosts in choice tests offering wasps one old and one young coccinellid.

\begin{tabular}{lccccccccc}
\hline \multirow{2}{*}{ Host sex } & \multicolumn{4}{c}{ Old hosts } & & \multicolumn{3}{c}{ Young hosts } \\
\cline { 2 - 3 } & $\begin{array}{c}\text { No. of times } \\
\text { attacked first }\end{array}$ & No. infected & $\begin{array}{c}\text { Total no. } \\
\text { of eggs }\end{array}$ & $\begin{array}{c}\text { Range of no. of } \\
\text { eggs per host }\end{array}$ & $\begin{array}{c}\text { No. of times } \\
\text { attacked first }\end{array}$ & No. infected & $\begin{array}{c}\text { Total no. } \\
\text { of eggs }\end{array}$ & $\begin{array}{c}\text { Range of no. of } \\
\text { eggs per host }\end{array}$ \\
\hline Female & 9 & 24 & 63 & $1-6$ & 16 & 25 & 123 & $1-19$ \\
Male & 11 & 21 & 41 & $1-4$ & 14 & 19 & 74 & $1-11$ \\
Total & 20 & 45 & 104 & & 30 & 44 & 197 & \\
\hline
\end{tabular}

1985). Van Alphen \& Thunnissen (1983) demonstrated that the pteromalid Pachycrepoides vindemiae, which parasitises drosophilid pupae, is reluctant to oviposit in pupae that have previously been parasitised by other species. Previously parasitised pupae were shown to be of lower quality to $P$. vindemiae than unparasitised pupae. Another parasitoid of drosophilids, the braconid Asobara tabida, selects host species on the basis of their quality, the probabilty of a host species being rejected for oviposition being inversely correlated to larval survival within that host (van Alphen \& Drijver, 1982; van Alphen \& Janssen, 1982; van Alphen \& Vet, 1986; Janssen, 1989).

The $D$. coccinellae-C. septempunctata situation, in respect of parasitoid fitness, appears to be similar, if less extreme, to that found by van Alphen \& Drijver (1982) who demonstrated that larvae of the parasitoid wasp $A$. tabida were only able to survive in young larvae of $D$. melanogaster. In the case of $D$. coccinellae some parasitisations of what might be deemed low quality (i.e. old) hosts, are successful.

It is not known how D. coccinellae distinguishes between young and old ladybirds. Either visual or olfactory cues may be involved. The ground colour of overwintered adults is substantially darker red than that of recently eclosed $C$. septempunctata, so that they are easily distinguished, at least by the human eye. However, as the levels of PI of old and young hosts did not differ, visual discrimination in the initial stages of interaction seems unlikely. It is possible that host colour has a role to play at close quarters, but the alternative explanation of olfactory cues seems more probable. For example, chemicals secreted by the adult ladybirds may provide information to the parasitoid. Such chemicals (kairomones) have previously been reported to be used in host location by hymenopteran parasitoids (e.g. Sternlicht, 1973), but whether they are used in assessing host suitability has not been demonstrated.

If kairomones are involved here, volatiles that are picked up by the parasitoid before tactile contact are probably of little significance in determining host age as the rate of pursuance and investigation did not differ between young and old potential hosts. More probable is that surface chemicals, detected by wasps when they touch a coccinellid with their antennae, or occsasionally their legs, are involved in the transition from PI to OS. In some studies, surface chemicals have been shown to be recognised by parasitoids and to elicit oviposition behaviour (see Arthur, 1981 for review). For example, Strand \& Vinson $(1982,1983)$ found that the scelionid Telenomus heliothidis, an egg parasitoid of the moth Heliothis vires- cens, will attempt to oviposit on glass beads covered by an accessory gland protein of the female moth, but not on uncoated glass beads. The data presented in Table 1 suggest that a host-age-dependent decision as to whether or not to insert the ovipositor, may be made even later, i.e. after the OS has been adopted. The proportion of parasitoids that proceded from OS to OA is 0.648 for young hosts (sexes combined), but only 0.476 for old hosts. Chemical cues from the surface of the abdomen and picked up by sensory cells on the ovipositor may allow discrimination at this stage

The significantly greater number of $D$. coccinellae eggs found in females compared to males, in the second set of tests (Table 3), may also reflect host assessment. This may simply be a function of the greater mean size of female compared to male C. septempunctata, leading to a higher encounter rate with females. However, it is also feasible that $D$. coccinellae may be actively preferring to oviposit in female hosts. Many parasitoids are known to insert their ovipositor into potential hosts but fail to lay an egg (Godfray, 1994). Experimental evidence suggests that, in some of these cases at least, the decision to lay an egg depends on chemical stimulae obtained by the parasitoid from the interior of the host, for example, the ichneumonid Itoplectis conquisitor can be induced to oviposit into dummy hosts of plastic film if these are filled with host haemolymph, but not those filled with saline or distilled water (Arthur et al., 1969; Hegdekar \& Arthur, 1973). As the prevalence of $D$. coccinellae has been reported to be higher in female than in male hosts in some Scottish samples of C. septempunctata (Geoghegan et al., 1997), specific tests designed to investigate differential host sex selection by this wasp would be valuable.

ACKNOWLEDGEMENTS. We wish to thank D. Bertrand for technical support. We acknowledge the Scottish Office Agriculture, Environment and Fisheries Department for supporting this research in part. Work in Cambridge was conducted in research facilities funded by the Wolfson Foundation. An anonymous referee made some very useful comments on a pervious draft of this paper.

\section{REFERENCES}

ALPHEN J.J.M. VAN 1980: Aspects of the foraging behaviour of Tetrastichus asparagi Crawford and Tetrastichus spec. (Eulophidae), gregarious egg parasitoids of the asparagus beetles Criocerus asparagi L. and C. duodecimpunctata L. (Chrysomelidae). Neth. J. Zool. 30: 307-325.

Alphen J.J.M. van \& DRIJver R.A.B. 1982: Host selection by Asobara tabida Nees (Braconidae: Alysinae) a larval parasitoid of fruit inhabiting Drosophila species. I. Host stage selec- 
tion with Drosohila melanogaster as host. Neth. J. Zool. 32: 215-231.

Alphen J.J.M. van \& JAnssen A.R.M. 1982: Host selection by Asobara tabida Nees (Braconidae: Alysinae), a larval parasitoid of fruit inhabiting Drosophila species. II. Host species selection. Neth. J. Zool. 32: 215-231.

Alphen J.J.M. van \& ThunNisen I. 1983: Host selection and sex allocation by Pachycrepoides vindemiae Rondani (Pteromalidae) as a facultative hyperparasitoid of Asobara tabida Nees (Braconidae: Alysiinae) and Leptopilina heterotoma (Cynipoidea: Eucoilidae). Neth. J. Zool. 33: 497-514.

ALPHEN J.J.M. VAN \& VET L.E.M. 1986: An evolutionary approach to host finding and selection. In Waage J.K. \& Greathead D. (eds): Insect Parasitoids. Academic Press, London, pp. 23-61.

ARTHUR A.P. 1981: Host acceptance. In Nordlund D.A., Jones R.L. \& Lewis W.J. (eds): Semiochemicals, Their Role in Pest Control, John Wiley, New York, pp. 97-120.

Arthur A.P., Hegdekar B.M. \& Rollins L. 1969: Component of the host haemolymph that induces oviposition in a parasitic wasp. Nature (London) 223: 966-967.

Cerrngier P. \& Hodek I. 1996: Enemies of Coccinellidae. In Hodek I. \& Honěk A.: Ecology of Coccinellidae. Kluwer Academic Publishers, Dordrecht, pp. 319-350.

Geoghegan I.E., Thomas W.P. \& Majerus M.E.N. 1997: Notes on the coccinellid parasitoid Dinocampus coccinellae (Schrank) (Hymenoptera: Braconidae) in Scotland. Entomologist 116: 179-184.

Geoghegan I.E., Majerus T.M.O. \& Majerus M.E.N. 1998: Differential parasitisation of imaginal and pre-imaginal Coccinella 7-punctata (Coleoptera: Coccinellidae) by Dinocampus coccinellae (Schrank) (Hymenoptera: Braconidae). Eur. J. Entomol. 95: 571-579

Godfray H.C.J. 1994: Parasitoids. Princeton University Press, Princeton, $473 \mathrm{pp}$.

Hegdekar B.M. \& Arthur A.P. 1973: Host haemolymph chemicals that induce oviposition in the parasite Itoplectis conquisitor (Hymenoptera: Ichneumonidae). Can. Entomol. 105: 787-793.

HopPeR K.R. \& KING E.G. 1984: Preference of Microplitis croceipes (Hymenoptera: Braconidae) for instars and species of Heliothis (Lepidoptera: Noctuidae). Envir. Entomol. 13: $1145-1150$.

Hurst G.D.D., McMeechan F.K. \& Majerus M.E.N. 1998: Phoridae (Diptera) parasitizing Coccinella septempunctata (Coleoptera: Coccinellidae) select older prepupal hosts. Eur. J. Entomol. 95: 179-181.

JANSSEN A. 1989: Optimal host selection by Drosophila parasitoids in the field. Funct. Ecol. 3: 469-479.

JuLiano S.A. 1982: Influence of host age on host acceptability and suitability for a species of Trichogramma (Hymenoptera: Trichogrammatidae) attacking aqautic Diptera. Can. Entomol. 114: $713-740$.
Kouamé K.L. \& Mackauer M. 1991: Influence of aphid size, age and behaviour on host choice by the parasitoid wasp Ephedrus californicus: A test of host-size models. Oecologia 88: 197-203.

KraAijeveld A.R., Nowee R.W. \& Najem R.W. 1995: Adaptive variation in host-selection behaviour of Asobara tabida, a parasitoid of Drosophila larvae. Funct. Ecol. 9: 113-118.

LEWIS W.J. \& REDLINGER L.J. 1969: Suitability of eggs of the almond moth Cadra cautella of various ages for parasitism by Trichogramma evanescens. Ann. Entomol. Soc. Am. 62: 1482-1484.

LuCK R.F., Podoler H. \& KFIR R. 1982: Host selection and egg allocation behaviour by Aphytis melinus and Aphytis lignanensis: a comparison of two facultatively gregarious parasitoids. Ecol. Entomol. 7: 397-408.

Majerus M.E.N., Kearns P.W.E., Forge H. \& Ireland H. 1989: Ladybirds as teaching aids: I: Collecting and culturing. $J$. Biol. Educ. 23: 85-95.

Marston N. \& Ertle L.R. 1969: Host age and parasitism by Trichogramma minutum (Hymenoptera: Trichogrammatidae). Ann. Entomol. Soc. Am. 62: 1476-1482.

NeChOls J.R. \& KIKUCHI R.S. 1985: Host selection of the spherical mealybug (Homoptera: Pseudococcidae) by Anagyrus indicus (Hymenoptera: Encyrtidae): Influence of host stage on parasitoid oviposition, development, sex ratio and survival. Envir. Entomol. 14: 32-37.

PAK G.A. 1986: Behavioural variations among strains of Trichogramma spp. A review of the literature on host-age selection. J. Appl. Entomol. 101: 55-64.

Pills J.W.A.M., HofKer K.D., van StaAlduinen M.J. \& VAN ALPHEN J.M. 1995: Interspecific host discrimination and competition in Apoanagyrus (Epidinocarsis) lopezi and A. (E.) diversicornis, parasitoids of the cassava mealybug Phenacoccus manihoti. Ecol. Entomol. 20: 326-332.

Richerson J.V. \& DeLoach C.J. 1972: Some aspects of host selection by Perilitus coccinellae. Ann. Entomol. Soc. Am. 65 : 834-839.

Sternlicht M. 1973: Parasitic wasps attracted by the sex pheromone of their coccid host. Entomophaga 18: 339-342.

STRAND M.R. 1986: The physiological interactions of parasitoids with their hosts and their influence on reproductive strategies. In Waage J.K. \& Greathead D. (eds): Insect Parasitoids. Academic Press, London, pp. 97-136.

Strand M. R. \& Vinson S. B. 1982: Behavioural response of the parasitoid, Cardiochiles nigriceps to a kairomone. Entomol. Exp. Appl. 31: 308-315.

Strand M.R. \& Vinson S.B. 1983: Factors affecting host recognition and acceptance in the egg parasitoid Telenomus heliothidis (Hymenoptera: Scelionidae). Envir. Entomol. 12: 1114-1119.

Received May 22, 1998; accepted March 28, 2000 